\title{
Cardiovascular risk factors in hypopituitary GH-deficient adults
}

\author{
Johan Verhelst and Roger Abs ${ }^{1}$ \\ Department of Endocrinology, ZNA Middelheim, B-2020 Antwerp, Belgium and ${ }^{1}$ Department of Endocrinology, University of Antwerp, B-2610 Antwerp, \\ Belgium \\ (Correspondence should be addressed to R Abs; Email: roger.abs@ua.ac.be)
}

( J Verhelst and R Abs contributed equally to this work)

\begin{abstract}
Design: Data on lipids, body composition, and blood pressure (BP) from all published KIMS papers are summarized and compared with a literature review.

Results: KIMS data confirm and extend previous research showing that adults with GH deficiency (GHD) have an adverse cardiovascular risk profile. GHD patients have high levels of dyslipidemia, elevated body mass index, unfavorable waist-to-hip ratio and body composition, and a high risk of hypertension. These abnormalities are likely to explain the increased cardiovascular mortality observed in patients with hypopituitarism. When given GH replacement therapy, an improvement is seen in KIMS as well as earlier studies for lipid profile, body composition, and BP. The added value of the different KIMS papers over previous research is that KIMS involves a much larger number of patients, that lipid concentrations and IGF 1 are measured in a single central laboratory, and that the effects of GH replacement therapy can be followed longer than the duration of earlier trials. By the large number of patients, KIMS gives insight into the effects of GH in different patients' subgroups such as elderly patients, patients with idiopathic GHD, patients with craniopharyngioma, patients after irradiation, and so on. In addition, KIMS has made it possible to calculate more exactly the influence of baseline parameters on these cardiovascular risk parameters and their response to $\mathrm{GH}$.

Conclusions: Taken together, data from KIMS confirm earlier knowledge about the important benefits of GH replacement therapy, but also on the use of GH in specific subgroups such as isolated GHD, patients above 65 years, and patients after irradiation. No subgroup yet has been identified as not responding well to $\mathrm{GH}$.
\end{abstract}

European Journal of Endocrinology 161 S41-S49

\section{Introduction}

Retrospective studies have shown that the risk of premature death is elevated in hypopituitary patients receiving conventional hormone replacement therapy without $\mathrm{GH}$, and that the increased risk was mainly due to an increased prevalence of cardiovascular disease (1-5). The excess mortality and the increased cardiovascular and cerebrovascular morbidity have also been confirmed in one large prospective study (6). GH deficiency (GHD) is the most likely explanation for this finding (7), although over- or under-replacement of other pituitary hormones may also be implicated $(8,9)$.

The hypothesis that GHD increases the risk of cardiovascular disease is supported by a series of risk factors common to the adult GHD syndrome, such as adverse lipid profiles (10-12), increased blood pressure

This paper forms part of a special issue on $\mathrm{KIMS}^{\circledR}$ and ACROSTUDY $^{\mathrm{TM}}$. Pfizer Inc. has supported the publication of this special issue.
(BP), abnormal body composition $(13,14)$, increased body weight $(15,16)$, increased coagulability (17), and increased markers of inflammation (18), leading to an accelerated atheromatosis.

A large number of prospective randomized clinical trials have repeatedly shown significant improvement in these parameters with $\mathrm{GH}$ replacement therapy, but these trials are usually hampered by small number of patients or a limited study period (3-12 months). This is due to the rarity of the disease making it difficult to recruit large number of patients for clinical trials of long duration. The KIMS (Pfizer International Metabolic Database) database, on the other hand, is not a randomized clinical trial but a pharmacovigilance study of patients on GH replacement therapy. KIMS has made it possible to follow a very large cohort of patients on GH replacement therapy during an extended period of time, and despite the absence of a randomized untreated control group has turned out to be a useful scientific tool as well. KIMS permitted in larger groups of patients to confirm, or not, observations from earlier 
randomized trials, and to analyse specific subgroup of patients split according to country, etiology, hormonal status, therapeutic options, and other conditions. The aim of this review is to present the KIMS publications on lipid profile, body composition, and BP in GHD adults and to evaluate the effect of $\mathrm{GH}$ replacement on both issues, in respect to the findings in the literature from other studies.

\section{Lipids}

\section{Effect of GH on lipids}

GH status in healthy subjects is an independent determinant of total cholesterol, low-density lipoprotein (LDL)-cholesterol, and triglycerides (19). GH has physiological effects on both very low-density lipoprotein (VLDL) and cholesterol metabolism, which explains the lipid disturbances observed in patients with GHD. Although GH stimulates VLDL apoB secretion by increasing intrahepatic lipid availability, it has been suggested that $\mathrm{GH}$ replacement improves the lipid profile by increasing the removal of VLDL particles by upregulating LDL receptors and modifying the VLDL composition (20). However, as VLDL synthesis remains elevated, serum triglycerides levels may not normalize during GH therapy. Moreover, GH stimulates the expression and activity of key enzymes involved in cholesterol synthesis and bile acid metabolism. By contrast, in GHD, reduced activity of cholesterol $7 \alpha$-hydroxylase results in intrahepatic cholesterol accumulation. This will downregulate LDL receptor numbers and increase 3-hydroxy-3-methylglutarylcoenzyme A reductase activity, which will subsequently increase cholesterol synthesis (21).

\section{Lipids of GH-deficient patients in clinical studies}

A series of clinical trials in GHD adults have studied the adverse lipid profile. The results of these trials are presented in the 10 years of KIMS book, chapter 12 (22).

de Boer et al. (23) evaluated the lipid profile in 64 young adults with GHD who were compared with an age- and gender-matched control group. Total cholesterol, LDL-cholesterol, and apoB levels were significantly higher in GH-deficient patients, while high-density lipoprotein (HDL)-cholesterol and triglycerides were normal. An inverse association between insulin-like growth factor 1 (IGF1) and LDL indicated that the abnormality in lipid metabolism could be related to the severity of GHD.

Sanmarti et al. (24) conducted a retrospective study of the health status of 926 hypopituitary patients with adult-onset GHD who were not treated with GH, including 1-year follow-up data, which were available in 356 patients. Clinical evaluations and laboratory tests showed a higher incidence of cardiovascular risk factors. Total cholesterol, LDL-cholesterol, and triglyceride levels were significantly higher, and HDL-cholesterol levels were significantly lower, compared with those of a reference population.

Abdu et al. (12) compared the serum lipid and lipoprotein levels of 50 hypopituitary adults with GHD on conventional hormone replacement with those of 45 healthy matched controls. Serum triglyceride levels were significantly increased in male and female GHD patients, total cholesterol and LDL-cholesterol were significantly increased in male patients, HDLcholesterol was significantly reduced in female patients, the ratio of total- to HDL-cholesterol was significantly increased in both male and female patients, and apoA-I levels were significantly reduced in female patients. Risk factor modeling showed an increased coronary risk associated with hypopituitarism, particularly among females, due largely to the abnormal lipid profile, which appeared to be related to GHD either directly or indirectly through central adiposity.

\section{Lipids of GH-deficient patients in KIMS}

In the first KIMS paper describing the characteristics of 1034 adult GHD, possibly the most striking finding was the elevated total cholesterol and triglycerides concentrations, especially in females, compared with large epidemiological studies (11).

The largest series of adult GHD patients in which the lipid profile was studied before the replacement of $\mathrm{GH}$ comes from a KIMS publication in 2006 (25). A total of 2589 adult patients ( $51 \%$ males; mean age 44 years) with severe GHD were analyzed at baseline. Similar to older studies, total cholesterol was high with a mean value of $5.9 \pm 1.3 \mathrm{mmol} / \mathrm{l}$. The overall mean LDLcholesterol concentration was $3.7 \pm 1.1 \mathrm{mmol} / \mathrm{l}$, following the same pattern as for total cholesterol regarding age and gender. The geometric mean of triglycerides was $1.8 \mathrm{mmol} / \mathrm{l}$ (10-90th percentile: 0.9-3.8). The overall mean for HDL-cholesterol was $1.2 \pm 0.4 \mathrm{mmol} / \mathrm{l}$.

\section{Influence of baseline variables on lipids of GH-deficient patients in KIMS}

The influence of baseline variables has specifically been studied in one large KIMS study (25). Overall, a profound effect was found on total and LDL-cholesterol, while HDL-cholesterol and triglycerides did not show important changes.

Gender Females showed a $0.2 \mathrm{mmol} / \mathrm{l}$ higher total cholesterol than males $(P<0.0001)$, without statistical significance between pre-menopausal and post-menopausal women. Females showed a $0.2 \mathrm{mmol} / \mathrm{l}$ higher HDL-cholesterol than males $(P<0.0001)(25)$. 
Age Total cholesterol increased across age categories from $5.0 \mathrm{mmol} / \mathrm{l}$ in the $<20$ age category up to $6.1 \mathrm{mmol} / \mathrm{l}$ in the $40-49$ age category; thereafter, no further increase was observed ( $P$ for linear age trend $<0.0001$; Fig. 1). Triglycerides increased by age $(P<0.0001)$, but leveled off in a similar fashion to the other lipid variables, and HDL-cholesterol remained constant (25).

Smoking Mean total cholesterol concentration was $0.2 \mathrm{mmol} / \mathrm{l}(3.4 \%)$ higher in smokers $(P=0.008)(25)$.

Epilepsy Mean total cholesterol concentration was $0.4 \mathrm{mmol} / \mathrm{l}(6.8 \%)$ higher in patients receiving antiepileptic drugs $(P<0.0001)(25)$.

Diabetes mellitus Mean total cholesterol concentration was $0.3 \mathrm{mmol} / \mathrm{l}(5.0 \%)$ lower in patients with diabetes mellitus $(P=0.03)(25)$.

Lipid lowering drugs Mean total cholesterol concentration was $0.2 \mathrm{mmol} / \mathrm{l}(3.4 \%)$ higher in patients taking lipid-lowering drugs $(P=0.05)(25)$. The additive effect of $\mathrm{GH}$ and statins has also been described in patients with hyperlipidemia (26).

Onset of GHD, duration of GHD, severity of hypopituitarism, severity of GHD, etiology, radiotherapy, body mass index (BMI), waist-to-hip ratio (WHR), and waist circumference did not influence significantly the baseline total cholesterol concentration (25).

\section{Effect of GH replacement on lipids in clinical studies}

A large series of clinical trials in GHD adults receiving $\mathrm{GH}$ replacement have studied the adverse lipid profile. The results of these trials are summarized in the 10 years of KIMS book, chapter 12 (22). Although there have

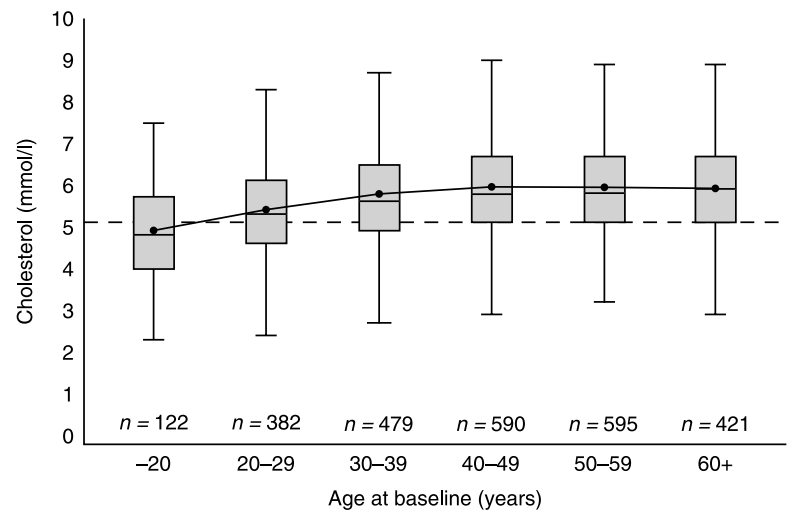

Figure 1 Total cholesterol baseline concentrations in 2589 GHD patients by age groups. Median, 10-25-75-90 percentile. The solid line represents the mean trend. The dashed line represents the target value of $5.2 \mathrm{mmol} / \mathrm{l}$. (Abs et al. European Journal of Endocrinology 2006155 79-90. Reproduced with kind permission of the European Society of Endocrinology) (25). been a number of negative results $(27,28)$, the majority of studies demonstrate a significant reduction in total and LDL-cholesterol during GH therapy, associated with an improvement of LDL receptor function resulting in an increased uptake of LDL-cholesterol. In contrast to the changes found in LDL-cholesterol metabolism, the abnormalities observed in the metabolism of the triglyceride-rich lipoproteins appear not to be corrected. Indeed, triglyceride level, LDL particle size, and HDL level remained mostly unaffected by GH replacement. This may be explained by the relative hyperinsulinemia induced by $\mathrm{GH}$ and the availability of free fatty acids, resulting in an increased hepatic VLDL secretion (29). Hypertriglyceridemia ensues despite the GH-induced reduction in visceral adiposity.

\section{Effect of GH replacement on lipids in KIMS}

In the first KIMS paper related to the effect of GH replacement in 665 adult GHD patients, it was observed that an amelioration in the lipid profile was present, most significantly in females (30).

The largest publication reporting the effect of $\mathrm{GH}$ upon the lipid profile is the KIMS paper also covering the baseline lipid characteristics (25). The data are based on 1206 patients after 1 and 2 years of GH treatment.

Statistically significant reductions in total cholesterol were observed after both 1 year and 2 years of $\mathrm{GH}$ replacement therapy: $-0.4 \mathrm{mmol} / \mathrm{l}(-6.8 \%$; $P<0.0001)$ and $-0.5 \mathrm{mmol} / \mathrm{l}(-8.5 \% ; P<0.0001)$ respectively. The additive effect during the second year of treatment was small, $-0.1 \mathrm{mmol} / \mathrm{l}$, but still significant compared with the first year $(P=0.001)$. The major change in total mean cholesterol is accounted for by the change in mean LDL-cholesterol, which was $-0.3 \mathrm{mmol} / \mathrm{l}$ after 1 year $(P<0.0001)$ and $-0.4 \mathrm{mmol} / \mathrm{l}$ after 2 years $(P<0.0001)$. Mean HDLcholesterol changed from 1.3 to $1.2 \mathrm{mmol} / \mathrm{l}$ after 2 years of treatment $(P<0.0001)$. Although this change was minimal, it was statistically significant. No statistically significant changes in triglycerides were observed.

\section{Influence of baseline variables on effect of GH therapy on lipids in KIMS}

Baseline cholesterol The higher the baseline value, the larger the absolute decrease in cholesterol, even after adjustment for regression to the mean: $\Delta(\mathrm{mmol} / \mathrm{l}) /(\mathrm{mmol} / \mathrm{l}$ at baseline $)=-0.06 \quad(P=0.01)$. This relationship would predict that a patient with a hypothetical baseline value of $7.5 \mathrm{mmol} / \mathrm{l}$ would demonstrate a change in cholesterol of 7.5 $\times(-0.06)=-0.45 \mathrm{mmol} / \mathrm{l}$ after 1 year of treatment. After 2 years of treatment, these observations were strengthened in all subgroups $(P<0.0001)$. The proportional effect per $\mathrm{mmol} / \mathrm{l}$ at baseline was increased to $-0.11(P=0.0006)(25)$. 
Time of treatment A descriptive model indicated that improvement in total cholesterol concentrations was largest during the first year of treatment. During the second year of treatment, the improvement was smaller (25).

Gender Females had on average $0.3 \mathrm{mmol} / \mathrm{l}$ higher mean cholesterol values than males $(95 \%$ confidence interval, CI: 0.2-0.4). Otherwise, males and females showed the same pattern of change (Fig. 2) (25). The higher baseline cholesterol levels in females may partly explain the higher incidence of cardiovascular burden compared with males $(3,6)$.

$\boldsymbol{A g e}$ Total cholesterol levels were similarly increased in patients older than 65 years of age compared with younger patients and the response to $\mathrm{GH}$ replacement was of similar magnitude (31).

Childhood-onset GHD Whatever the diagnosis responsible for the pituitary deficiency, elevated cholesterol
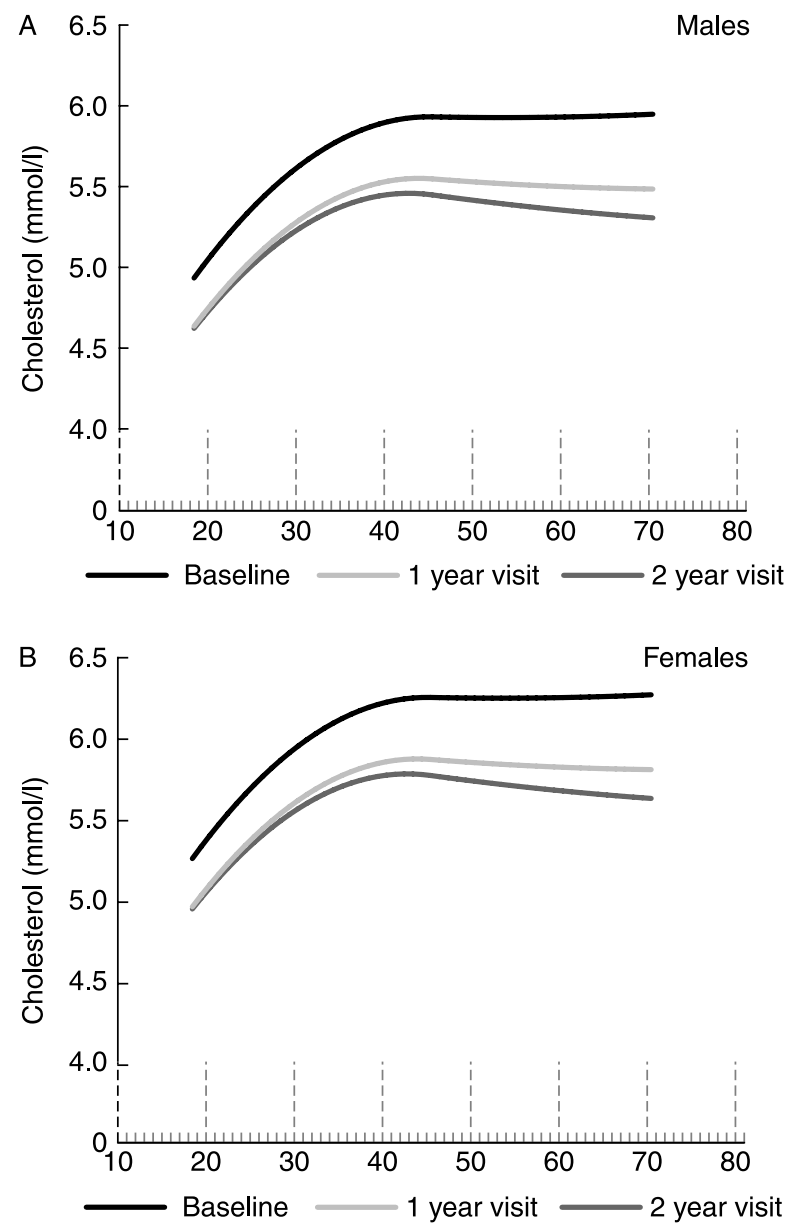

Figure 2 Mean total cholesterol concentration by age and gender at baseline and after 1 year and 2 years of $\mathrm{GH}$ replacement for the subset of 1206 GHD patients with 2-year longitudinal follow-up in males (A) and females (B). (Abs et al. European Journal of Endocrinology 2006155 79-90. Reproduced with kind permission of the European Society of Endocrinology) (25). levels were observed in any circumstance and they decreased during GH replacement (32).

Isolated GHD Patients with isolated GHD and multiple pituitary hormone deficiencies (MPHD) presented with comparably elevated total cholesterol concentrations, responding adequately to $\mathrm{GH}$ therapy (33).

Craniopharyngioma There were no differences in total cholesterol between patients with craniopharyngiomas (CPs) and a control group consisting of non-functioning pituitary adenomas (NFPA), both responding to $\mathrm{GH}$ replacement similarly (34).

Sheehan's syndrome The increased total cholesterol levels decreased significantly during GH therapy (35).

Irradiation The total cholesterol level was increased in both irradiated and non-irradiated patients, decreasing both during $\mathrm{GH}$ replacement, although somewhat better in the irradiated group (36).

\section{Body composition}

\section{Effect of GH on body composition}

Multiple in vitro and in vivo studies have shown that $\mathrm{GH}$ is a lipolytic and anabolic hormone and has an antinatriuretic action (37). Each of these properties is known to have an impact on body composition.

\section{Measurement of body composition}

In KIMS as well as in many clinical studies, body composition is measured by body impedance analysis (BIA) or dual-energy X-ray absorptiometry (DXA). These techniques are based on a two-compartment model (BIA) or three-compartment-model (DXA) of body composition and rely on assumptions derived from healthy subjects, e.g. constant hydration state of lean body mass (LBM), which may not be completely valid in adult GHD (normal ratio of total body water to $\mathrm{LBM}$ is $73 \%$ and fat mass (FM) is calculated by subtracting LBM from weight). As GHD is associated with a dehydration state of LBM at baseline, LBM is underestimated and FM overestimated (38). Nevertheless, the findings with DXA and BIA resemble closely those with other techniques not based on this model such as computer tomography (CT) scanning (39), anthropometric measurements (15), and magnetic resonance imaging (40) and are therefore considered useful despite their limitations.

\section{Body composition of GH-deficient patients in clinical studies}

Obesity is common in GHD patients. In an exemplary study of 64 patients, BMI was $27.5 \mathrm{~kg} / \mathrm{m}^{2}$ (13), 
indicating abnormal weight in the majority of patients. But even when matched for BMI, GHD patients have a more unfavorable body composition compared with controls. Their body fat appears to be on average 6-7 kg higher than expected (41-43). Fat percentage measured by BIA in males in an exemplary study was $29.3 \%(6.1 \%$ higher than in controls $)$ and in females $34.6 \%$ (5.3\% higher than in controls) (13). This excess FM is situated preferentially in abdominal and visceral sites. At the same time, a reduction in LBM was observed of about $4 \mathrm{~kg}(41,44)$. Finally, GHD patients are dehydrated (38) and the loss of extracellular water (ECW) is estimated at $0.7 \mathrm{~kg}$ for men and $2.4 \mathrm{~kg}$ for women (42).

\section{Body composition of GH-deficient patients in KIMS}

The KIMS database has given insight into BMI and body composition data of a much larger group of GHD patients than in earlier studies. Besides confirming earlier data, KIMS has allowed us to look at differences according to baseline characteristics such as different etiologies of GHD, the effect of cranial irradiation, the effect of age of disease onset, isolated versus multiple pituitary insufficiency, the impact of use of estrogens and corticosteroids, and so on.

In a first KIMS analysis in 1999 of 1034 patients, Abs et al. (11) confirmed excess weight in KIMS patients in both males and females of respectively 28.2 and $28.8 \mathrm{~kg} / \mathrm{m}^{2}$, and showed this to be higher than the control population from PROCAM and MONICA with values of 25.3 and $26.5 \mathrm{~kg} / \mathrm{m}^{2}$ for men and 24.3 and $25.8 \mathrm{~kg} / \mathrm{m}^{2}$ for women $(P<0.001)$. In a new analysis, 7 years later, of 2589 KIMS patients, mean BMI was $28.2 \mathrm{~kg} / \mathrm{m}^{2}$ and $32 \%$ of patients had a BMI above 30 (25), showing once more on a large scale that GHD is a risk factor for obesity. The unfavorable body composition of GHD patients was clearly present as well. Excess visceral fat was demonstrated in 2589 patients, in which waist circumference at baseline was above $102 \mathrm{~cm}$ in $40 \%$ of males and above $88 \mathrm{~cm}$ in $56 \%$ of females (25). In a KIMS study comparing NFPA with CPs, FM in 370 patients with a NFPA was $26.5 \%$ (normal <19\%) in males and 39.4\% (normal <30\%) in females (34). These data confirm in a very large group of patients the typical picture of a GHD patient: overweight; high percentage fat; excess visceral fat.

Elderly patients, patients after irradiation, those with diabetes, patients with a CP, and those taking antiepileptic drugs were even more likely to have fat accumulation (25). By contrast, those with isolated GH deficiency and childhood-onset disease were less likely. There was no difference in weight, body composition, or WHR between women taking different estrogen therapies (45). Patients on doses of hydrocortisone above $20 \mathrm{mg}$ /day and on dexamethasone or prednisolone have a more unfavorable profile, while patients on doses equivalent to $20 \mathrm{mg}$ hydrocortisone per day resemble steroid-sufficient patients (46).

\section{Effect of GH replacement therapy on body composition in clinical studies}

In a large meta-analysis of 37 trials containing data of 473 patients on $\mathrm{GH}$ replacement therapy for 6-12 months, BMI did not change significantly, indicating that other factors besides GHD play a role in maintaining a high weight. By contrast, body composition changed significantly with $\mathrm{GH}$ therapy: FM was reduced by a mean of $3.05 \pm 3.29 \mathrm{~kg}$ and LBM increased by $2.8 \pm 2.68 \mathrm{~kg}$ (47). The drop in FM is accompanied by a decrease in waist and WHR. No difference was seen in studies $<6$ months or $\geq 6$ months. In the first studies, high doses of GH were used, which often resulted in supraphysiological levels of IGF1 and many side effects. GH doses were therefore reduced in later trials aiming at IGF1 levels between 0 and 2 SDS without any loss of beneficial effect $(48,49)$. The variability in individual response to $\mathrm{GH}$ therapy is known to be important (50). On the other hand, when $\mathrm{GH}$ therapy is stopped, the effects are rapidly lost (51).

\section{Effect of GH replacement therapy on body composition in KIMS}

In an analysis of 2589 KIMS patients, GH therapy after 1 year gave no significant change in BMI (25). By contrast, GH therapy resulted in a significant reduction in FM of $2.1 \mathrm{~kg}$ (CI: 1.5-2.8) and a corresponding mean increase in LBM of $1.7 \mathrm{~kg}$ (CI: 1.3-2.2) if measured by DXA, and by respectively $1.2 \mathrm{~kg}$ (CI: $0.7-1.8)$ and $1.3 \mathrm{~kg}$ (CI: $0.7-1.9$ ) if measured by BIA. There was also a $1 \mathrm{~cm}$ decrease in waist (CI: 0.7-1.4) and an improvement in WHR $(-0.01)$. The percentage of patients with a waist circumference exceeding the target value during the treatment period dropped from 45 to 43\% $(P<0.0002)$.

\section{Influence of baseline and other variables on effect of GH therapy on body composition in clinical studies}

Treatment duration In studies with long-term followup, a progressive increase in weight is usually noticed, reflecting the natural tendency to gain weight with time: $1-5 \mathrm{~kg}$ after $5-10$ years $(52,53)$. In a large group of 118 patients, the effect of GH therapy on LBM and FM was sustained after 5 years: FM $-1.2 \mathrm{~kg}$ and LBM $+2.3 \mathrm{~kg}$, with more loss of FM after 1 year of therapy $(-2.4 \mathrm{~kg})$ and $0.9 \mathrm{~kg}$ increase again between years 1 and 2 , after which values remained largely stable (53). The effects also sustained after 10 years of GH therapy in a group of respectively 10 and 87 patients $(52,53)$. 
Gender The effect was independent from gender (47). In some studies, significantly more body fat (BF) is lost in men than in women (53).

Age The effect was independent from age (47).

Age at GHD onset No difference could be seen between patients with childhood- and adult-onset disease (47).

\section{Influence of baseline and other variables on effect of GH therapy on body composition in KIMS}

Treatment duration In a KIMS analysis of 2589 patients, a small but significant increase in BMI was noticed between 1 and 2 years of GH replacement therapy: $+0.3 \mathrm{~kg} / \mathrm{m}^{2}(P<0.0001)$, which was also reflected in a small rise in FM measured with BIA $(P=0.01)$ between 1 and 2 years, but not with DXA. By contrast, the effects on LBM remained the same after 2 years with BIA and increased further by $0.5 \mathrm{~kg}$ with DXA $(P=0.018)(25)$. One study comparing 48 patients on GH for 4 years with $23 \mathrm{GHD}$ patients not treated with GH showed more effect in the GH-treated group on FM $(-1.8$ vs $-0.2 \%)$ and LBM ( -1.5 vs $0.6 \%)$, although the difference was not significant (54).

Gender Women have a similar response to $\mathrm{GH}$ replacement as men when individualized GH-dosing schedules were employed (55).

Age GH replacement was as efficient in patients older than 65 compared with patients younger than 65 years (31). Waist circumference decreased equally by about $1 \mathrm{~cm}$ in patients $<45,45-55,55-65$, and $>65$ years.

Age at GHD onset KIMS patients with MPHD and childhood-onset disease $(n=602)$ were, at the introduction of GH treatment at baseline, a lot younger (27.8 vs 48.5 years) than patients with adult-onset disease $(n=1992)$, but responded in a similar way with changes in body composition after 1 year of $\mathrm{GH}$ replacement therapy (33).

Previous irradiation Patients with previous irradiation $(n=447)$ responded equally well to GH replacement therapy after 1 and 2 years than the other GHD $(n=630)$ patients $(36)$.

Etiology of GHD GH replacement after 1 year had an equal positive effect on body composition in patients with Sheehan's syndrome: LBM $+1.93 \mathrm{~kg}$ than in patients with a NFPA (35).

Patients with a CP did not lose FM after 2 years of GH replacement therapy in contrast to patients with a NFPA, but had an equal increase in LBM (34). CP patients also had a larger increase in BMI: 0.73 vs
$0.17 \mathrm{~kg} / \mathrm{m}^{2}$. In a study of 51 patients after traumatic brain injury, no significant changes were seen in waist, FM, and LBM compared with baseline after 1 year of GH replacement therapy (56).

Isolated versus multiple hormone deficiency Patients with adult-onset-isolated GHD $(n=89)$ responded to $\mathrm{GH}$ replacement therapy in a similar way as patients with MPHD $(n=1234)$, although the effect was less pronounced: decrease in FM after 1 year -0.3 vs $-1.6 \mathrm{~kg}(P<0.0001)$, LBM +0.5 vs $+1.1 \mathrm{~kg}(P<0.001)$, and waist -0.7 vs $-1.7 \mathrm{~cm}$ $(P<0.0001)(33)$.

Type of estrogen therapy There was no difference in FM or LBM response among patients with normal gonadal function and those taking different estrogen preparations after 1 year of GH therapy except for less change in WHR if the oral estrogen groups were combined (45). To obtain target IGF1 levels, patients taking ethinyl estradiol required almost twice the $\mathrm{GH}$ dose than patients with normal gonadal function and patients receiving transdermal estradiol.

Type of corticosteroid therapy One year of GH replacement induced a similar response among the different types of glucocortiosteroids and steroidsufficient patients (46). Therefore, the difference in anthropometry and metabolic risk at baseline in patients on doses of hydrocortisone above $20 \mathrm{mg} /$ day and on dexamethasone or prednisolone remained.

Prediction of effect Patients with a high WHR at baseline had a greater treatment response. The observed correlation, however, was weak (55).

\section{Blood pressure}

\section{Blood pressure of GH-deficient patients in clinical studies}

Whether patients with GHD have a change in BP is unclear. Many studies failed to show any influence (8). Some authors found GHD to be associated with higher diastolic BP in older and a lower systolic BP in younger GHD patients (57). One possible mechanism for the increased diastolic BP in GHD patients is an enhanced sympathetic nerve activity of central origin (58). GHD was associated with a changed circadian BP pattern with more than 30\% non-dippers during the night (59).

\section{Blood pressure of GH-deficient patients in KIMS}

In a KIMS study in 2586 patients, $15 \%$ of patients have a medical history of hypertension (25). BP was above the target value of $135 / 85$ in $26 \%$ of patients $(28 \%$ of 
men and $23 \%$ of women). BP increased with age, weight, and smoking. BP also showed a significantly positive correlation with IGF1 SDS.

\section{Effect of GH replacement therapy on BP in clinical studies}

A fall in diastolic BP with GH therapy and no change in systolic BP were observed in a large meta-analysis with BP data of $200 \mathrm{GHD}$ patients form 37 trials (47). During 24-h ambulatory BP in 22 patients, a significant decrease in systolic BP $(-5.8 \mathrm{mmHg})$ and diastolic BP $(-6.8 \mathrm{mmHg})$ was seen after 12 months of $\mathrm{GH}$ replacement and an increase in heart rate of 3.3 beats/min $(60)$.

\section{Effect of GH replacement therapy on BP in KIMS}

Although GH replacement therapy did not induce a significant change in the mean systolic and diastolic BP after 1 and 2 years of GH treatment (25), there was a significant decrease in the percentage of patients with $\mathrm{BP}$ exceeding the target values of $135 / 85 \mathrm{mmHg}$ during the treatment period (from 26 to $23 \%, P<0.004$ ).

\section{Other cardiovascular factors}

Other factors may influence the cardiovascular outcome of GDH patients, but they have not been systematically analyzed in KIMS publications. Although they may be important in the general picture, they cannot be discussed in detail in the scope of this KIMS review.

A prothrombotic state has been described in patients with hypopituitarism in whom plasma fibrinogen and plasminogen activator inhibitor-1 activity was increased (17), although this has not been confirmed in other studies $(61,62)$.

Inflammation is now understood to play a critical role in the development of atheroma. In patients with hypopituitarism receiving conventional replacement therapy, but not $\mathrm{GH}$, both serum interleukin- 6 and C-reactive protein levels are significantly elevated compared with controls $(18,63)$.

In adults with hypopituitarism and GHD, aortic compliance, an ultrasonographic measure of stiffness, was decreased (64), and carotid intima-media thickness, an ultrasonographic measure of risk of myocardial infarction and stroke, was increased $(65,66)$ compared with matched controls.

\section{Conclusion}

KIMS publications extend previous data from clinical trials confirming that adults with GHD have an adverse cardiovascular risk profile. GHD patients present with an adverse lipid profile, elevated BMI, increased waist circumference, abnormal body composition, and a high risk of hypertension. These abnormalities are likely to explain the increased cardiovascular mortality observed in patients with hypopituitarism whatever the etiology responsible for GHD.

KIMS publications have also shown that GH replacement therapy improves the clinical picture irrespective of causative factors, subgroups consisting of elderly patients, or with isolated GHD.

\section{Declaration of interest}

The authors disclose no potential conflicting relationship with Pfizer. KIMS $^{\circledR}$ is supported by Pfizer Inc. This paper forms part of a European Journal of Endocrinology supplement, supported by Pfizer Inc.

\section{References}

1 Rosén T \& Bengtsson B-Å. Premature mortality due to cardiovascular disease in hypopituitarism. Lancet 1990336 285-288.

2 Bates AS, Van't Hoff W, Jones PJ \& Clayton RN. The effect of hypopituitarism on life expectancy. Journal of Clinical Endocrinology and Metabolism 199681 1169-1172.

3 Bülow B, Hagmar L, Mikoczy Z, Nordström CH \& Erfurth EM. Increased cerebrovascular mortality in patients with hypopituitarism. Journal of Clinical Endocrinology and Metabolism 199746 75-81.

4 Bates AS, Bullivant B, Sheppard MC \& Steward PM. Life expectancy following surgery for pituitary tumours. Clinical Endocrinology 199950 315-319.

5 Svensson J, Bengtsson B-Å, Rosen T, Oden A \& Johannsson G. Malignant disease and cardiovascular morbidity in hypopituitary adults with or without growth hormone replacement therapy. Journal of Clinical Endocrinology and Metabolism 2004 89 3306-3312.

6 Tomlinson JW, Holden N, Hills RK, Wheatley K, Clayton RN, Bates AS, Sheppard MC \& Steward PM. Association between premature mortality and hypopituitarism. West Midland Prospective Hypopituitarism Group. Lancet 2001357 425-431.

7 Bengtsson B-A. Untreated growth hormone deficiency explains premature mortality in patients with hypopituitarism. Growth Hormone and IGF Research $1998 \mathbf{8} 480-485$.

8 Beshyah SA \& Johnston D. Cardiovascular disease and risk factors in adults with hypopituitarism. Clinical Endocrinology $1999501-15$.

9 Stewart PM \& Sheppard MC. Mortality and hypopituitarism. Growth Hormone and IGF Research 19999 15-19.

10 Beshyah SA, Henderson A, Niththyanathan R, Sharp P, Richmond W \& Johnston DG. Metabolic abnormalities in growth hormone deficient adults: carbohydrate tolerance and lipid metabolism. Endocrinology and Metabolism 19941 173-180.

11 Abs R, Bengtsson B-Å, Hernberg-Ståhl E, Monson JP, Tauber J-P, Wilton P \& Wüster C. GH replacement in 1034 growth hormone deficient adults: demographic and clinical characteristics, dosing and safety. Clinical Endocrinology 199950 703-713.

12 Abdu TA, Neary R, Elhadd TA, Akber M \& Clayton RN. Coronary risk in growth hormone deficient hypopituitary adults: increased predicted risk is due largely to lipid profile abnormalities. Clinical Endocrinology 200155 209-216.

13 Beshyah SA, Freemantle C, Thomas E, Rutherford O, Page B, Murphy M \& Johnston DG. Abnormal body composition and reduced bone mass in growth hormone deficient hypopituitary adults. Clinical Endocrinology 199542 179-189. 
14 Lonn L, Johansson G, Sjostrom L, Kvist H, Oden A \& Bengtsson B- $\AA$. Body composition and tissue distributions in growth hormone deficient adults before and after growth hormone treatment. Obesity Research 19964 45-54.

15 Jørgensen JO, Pedersen SA, Thuesen L, Jorgensen J, IngemannHansen T, Skakkebaek NE \& Christiansen JS. Beneficial effects of growth hormone treatment in GH-deficient adults. Lancet 1989 1 1221-1225.

16 Libber SM, Plotnick LP, Johanson AJ, Blizzard RM, Kwiterovich PO \& Migeon CJ. Long-term follow-up of hypopituitary patients treated with human growth hormone. Medicine 199069 46-55.

17 Johansson J-O, Landin K, Tengborn L, Rosén T \& Bengtsson B-Å. High fibrinogen and plasminogen activator inhibitor activity in growth hormone deficient adults. Arteriosclerosis and Thrombosis 199414 434-437.

18 Leonsson M, Hulthe J, Johannsson G, Wiklund O, Wikstrand J, Bengtsson B- $\AA$ \& Oscarsson J. Increased interleukin- 6 levels in pituitary-deficient patients are independently related to their carotic intima-media thickness. Clinical Endocrinology 200359 242-250.

19 Vahl N, Klausen I, Christiansen JS \& Jørgensen JO. Growth hormone status is an independent determinant of serum levels of cholesterol and triglycerides in healthy subjects. Clinical Endocrinology 199951 309-316.

20 Christ ER, Cummings MH, Albany E, Umpleby AM, Lumb PJ, Wierzbicki AS, Naoumova RP, Boroujerdi MA, Sönksen PH \& Russell-Jones DL. Effects of growth hormone (GH) replacement therapy on very low density lipoprotein apolipoprotein B100 kinetics in patients with adult GH deficiency: a stable isotope study. Journal of Clinical Endocrinology and Metabolism $1999 \mathbf{8 4}$ 307-316.

21 Rudling M, Parini P \& Angelin B. Growth hormone and bile acid synthesis. Key role for the activity of hepatic microsomal cholesterol $7 \alpha$-hydroxylase in the rat. Journal of Clinical Investigation 199799 2239-2245.

22 Abrams P \& Abs R. The Lipid profile in adult hypopituitary patients with growth hormone deficiency. In Growth Hormone Deficiency. 10 Years of KIMS, Eds R Abs \& U Feldt-Rasmussen, Oxford, UK: Oxford PharmaGenesis ${ }^{\text {TM }}$ Ltd, 2004 (ISBN 1-903539-02-1).

23 deBoer H, Blok GJ, Voerman HJ, Philips M \& Schouten JA. Serum lipid levels in growth hormone deficient men. Metabolism 199443 199-203.

24 Sanmarti A, Lucas A, Hawkins F, Webb SM \& Ulied A. Observational study in adult hypopituitary patients with untreated growth hormone deficiency (ODA study). Socio-economic impact and health status. Collaborative ODA (Observational GH Deficiency in Adults) Group. European Journal of Endocrinology 1999141 $481-489$.

25 Abs R, Feldt-Rasmussen U, Mattsson AF, Monson JP, Bengtsson B-Å, Góth MI, Wilton P \& Koltowska-Häggström M. Determinants of cardiovascular risk in 2589 hypopituitary growth hormone-deficient adults. European Journal of Endocrinology 2006 $15579-90$

26 Monson JP, Jönsson P, Koltowska-Häggström M \& Kourides I. Growth hormone replacement decreases serum total and LDL-cholesterol in hypopituitary patients on maintenance HMG CoA reductase inhibitor (statin) therapy. Clinical Endocrinology $200767623-628$.

27 Beshyah SA, Henderson A, Niththyananthan R, Skinner E, Anyaoku V, Richmond W, Sharp P \& Johnston DG. The effect of short and long-term growth hormone replacement therapy in hypopituitary adults on lipid metabolism and carbohydrate tolerance. Journal of Clinical Endocrinology and Metabolism $1995 \mathbf{8 0}$ 356-363.

28 Chrisoulidou A, Beshay SA, Rutherford O, Spinks TJ, Mayet J, Kyd P, Anyaoku V, Haida A, Ariff B, Murphy M, Thomas E, Robinson S, Foale R \& Johnston DC. Effect of 7 years of growth hormone replacement therapy in hypopituitary adults. Journal of Clinical Endocrinology and Metabolism 200085 3762-3769.
29 Christopher M, Hew FL, Oakley M, Rantzau C \& Alford F. Defects of insulin action and skeletal muscle glucose metabolism in growth hormone-deficient adults persist after 24 months of recombinant human growth hormone therapy. Journal of Clinical Endocrinology and Metabolism $1998 \mathbf{8 3} 1668-1681$.

30 Bengtsson B- $\AA$, Abs R, Bennmarker H, Monson JP, FeldtRasmussen U, Hernberg-Ståhl E, Westberg B, Wilton P \& Wüster $\mathrm{C}$. The effects of treatment and the individual responsiveness to growth hormone (GH) replacement therapy in 665 GH-deficient adults. KIMS Study Group and the KIMS International Board. Journal of Clinical Endocrinology and Metabolism 199984 3929-3935.

31 Monson JP, Abs R, Bengtsson B-Å, Bennmarker H, FeldtRasmussen U, Hernberg-Ståhl E, Thorén M, Westberg B, Wilton P \& Wüster C. Growth hormone deficiency and replacement in elderly hypopituitary adults. Clinical Endocrinology 200053 281-289.

32 Hoybye C, Jönsson P, Monson JP, Koltowska-Häggström M, Hána V, Geffner M \& Abs R. Impact of the primary aetiology upon the clinical outcome of adults with childhood-onset growth hormone deficiency. European Journal of Endocrinology 2007157 589-596.

33 Abs R, Mattsson AF, Bengtsson B-Å, Feldt-Rasmussen U, Goth MI, Koltowska-Häggström M, Monson JP, Verhelst J \& Wilton P. Isolated growth hormone $(\mathrm{GH})$ deficiency in adult patients: baseline clinical characteristics and responses to $\mathrm{GH}$ replacement in comparison with hypopituitary patients. A sub-analysis of the KIMS database. Growth Hormone and IGF Research 200515 349-359.

34 Verhelst J, Kendall-Taylor P, Erfurth EM, Price DA, Geffner M, Koltowska-Häggström M, Jonsson PJ, Wilton P \& Abs R. Baseline characteristics and response to 2 years of growth hormone $(\mathrm{GH})$ replacement of hypopituitary patients with $\mathrm{GH}$ deficiency due to adult-onset craniopharyngioma in comparison with patients with non-functioning pituitary adenoma: data from KIMS. Journal of Clinical Endocrinology and Metabolism 200590 4636-4643.

35 Keleştimur F, Jonsson P, Molvalilar S, Gomez JM, Auernhammer CJ, Colak R, Koltowska-Häggström M \& Goth MI. Sheehan's syndrome: baseline characteristics and effects of 2 years of growth hormone replacement therapy in 91 patients in KIMS - Pfizer International Metabolic Database. European Journal of Endocrinology 2005152 581-587.

36 Maiter D, Abs R, Johannsson G, Scanlon M, Jönsson PJ, Wilton P \& Kołtowska-Häggström M. Baseline characteristics and response to growth hormone $(\mathrm{GH})$ replacement of hypopituitary patients previously irradiated for pituitary adenoma or craniopharyngioma: data from KIMS (Pfizer International Metabolic Database). European Journal of Endocrinology 2006155 253-260.

37 Press M. Growth hormone and metabolism. Diabetes/Metabolism Reviews 19884 391-414.

38 de Boer H, Blok GJ \& Van der Veen EA. Clinical aspects of growth hormone deficiency in adults. Endocrine Reviews 199516 63-86.

39 Lönn L, Kvist H, Grangård U, Bengtsson B-Å \& Sjöström L. CT-determined body composition changes with recombinant human growth hormone treatment to adults with growth hormone deficiency. Basic Life Sciences 199360 229-231.

40 Snel YE, Brummer RJ, Doerga ME, Zelissen PM \& Koppeschaar HP. Adipose tissue assessed by magnetic resonance imaging in growth hormone-deficient adults: the effect of growth hormone replacement and a comparison with control subjects. American Journal of Clinical Nutrition 199561 1290-1294.

41 Binnerts A, Swart GR, Wilson JHP, Hoogerbrugge N, Pols HA, Birkenhager JC \& Lamberts SW. The effect of growth hormone administration in growth hormone deficient adults on bone, protein, carbohydrate and lipid homeostasis, as well as of body composition. Clinical Endocrinology 199237 79-87.

42 Rosén T, Eden S, Larson G, Wilhelmsen L \& Bengtsson B-Å. Cardiovascular risk factors in adults with growth hormone deficiency. Acta Endocrinologica 1993129 201-206.

43 Weaver JU, Monson JP, Noonan K, John WG, Edwards A, Evans KA \& Cunningham J. The effect of low dose recombinant growth 
hormone replacement on regional fat distribution, insulin sensitivity and cardiovascular risk factors in hypopituitary adults. Journal of Clinical Endocrinology and Metabolism 1995 $80153-159$.

44 Salomon F, Cuneo RC, Hesp R \& Sonksen PH. The effects of treatment with recombinant human growth hormone on body composition and metabolism in adults with growth hormone deficiency. New England Journal of Medicine 1989321 1797-1803.

45 Mah PM, Webster J, Jönsson P, Feldt-Rasmussen U, KoltowskaHäggström M \& Ross RJM. Oestrogen replacement in hypopituitary women of fertile years. Journal of Clinical Endocrinology and Metabolism 200590 5964-5969.

46 Filipsson H, Monson JP, Koltowska-Häggström M, Mattsson A \& Johannsson G. The impact of glucocorticoid replacement regimens on metabolic outcome and comorbidity in hypopituitary patients. Journal of Clinical Endocrinology and Metabolism $2006913954-3961$.

47 Maison P, Griffin S, Nicoue-Beglah M, Haddad N, Balkau B \& Chanson P. Impact of growth hormone treatment on cardiovascular risk factors in GH-deficient adults: a meta-analysis of blinded, randomised, placebo-controlled trials. Journal of Clinical Endocrinology and Metabolism 200489 2192-2199.

48 Ahmad AM, Hopkins MT, Thomas J, Ibrahim H, Fraser WD \& Vora JP. Body composition and quality of life in adults with growth hormone deficiency; effect of low-dose growth hormone replacement. Clinical Endocrinology 200154 709-718.

49 Mukherjee A, Monson JP, Jonsson PJ, Trainer PJ \& Shalet S. Seeking the optimal target range for insulin-like growth factor I during the treatment of adult growth hormone disorders. Journal of Clinical Endocrinology and Metabolism $2003 \mathbf{8 8}$ 5865-5870.

50 Johannsson G, Bengtson BA, Andersson B, Isgaard J \& Caidahl K. Long-term cardiovascular effects of growth hormone treatment in GH-deficient adults. Preliminary data in a small group of patients. Clinical Endocrinology 199645 305-314.

51 Biller BM, Sesmilo G, Baum HB, Hayden D, Schoenfeld D \& Klibanski A. Withdrawal of long-term physiological growth hormone (GH) administration: differential effects on bone density and body composition in men with adult-onset GH deficiency. Journal of Clinical Endocrinology 200085 970-976.

52 Gibney J, Wallace JD, Spinks T, Schnorr L, Ranicar A, Cuneo RC, Lockhart S, Burnand KG, Salomon F, Sonksen PH \& RusselJones D. The effects of 10 years of recombinant growth hormone in adult GH-deficient patients. Journal of Clinical Endocrinology and Metabolism 199984 2596-2602.

53 Gotherstrom G, Svensson J, Koranyi J, Alpsten M, Bosaeus I, Bengtsson B-Å \& Johansson G. A prospective study of 5 years of GH replacement therapy in GH-deficient adults: sustained effects on body composition, body mass and metabolic indices. Journal of Clinical Endocrinology and Metabolism 200186 4657-4665.

54 Fideleff HL, Boquete HR, Stalldecker G, Giaccio AV \& Sobrado PG. Comparative results of a 4-year study on cardiovascular parameters, lipid metabolism, body composition and bone mass between untreated and treated adult growth hormone deficient patients. Growth Hormone and IGF Research 200818 318-324.

55 Svensson J, Finer N, Bouloux P, Bevan J, Jonsson B, Mattsson AF, Lundberg M, Harris PE, Koltowska-Häggström M \& Monson on behalf of the KIMS International Board JP. Growth hormone (GH) replacement therapy in GH deficient adults: predictors of metabolic and clinical response. Growth Hormone and IGF Research 200717 67-76.

56 Casanueva FF, Leal Cerro A, Koltowska-Häggström M, Jonsson P \& Góth MI. Traumatic brain injury as a relevant cause of growth hormone deficiency in adults. A KIMS based study. Archives of Physical Medicine and Rehabilitation 20053 463-468.

57 Colao A, di Somma C, Cuocolo A, Spinelli L, Tedesco N, Pivonello R, Bonaduce D, Salvatore M \& Lombardi G. Improved cardiovascular risk factors and cardiac performance after 12 months of growth hormone replacement in young adult patients with GH deficiency. Journal of Clinical Endocrinology and Metabolism 200186 1874-1881.

58 Sverrisdottir YB, Elam M, Caidahl K, Soderling AS, Herlitz H \& Johannsson G. The effect of growth hormone (GH) replacement therapy on sympathetic nerve hyperactivity in hypopituitary adults: a double-blind, placebo-controlled, crossover, short-term trial followed by long-term open GH replacement in hypopituitary adults. Journal of Hypertension 200321 1905-1914.

59 Conceicao FL, de Rooij Mansur VA, Brasil RR \& Vaisman M. Ambulatory monitoring of blood pressure in growth hormone deficient adults. Blood Pressure Monitoring 20027 89-94.

60 Ahmad AM, Hopkins MT, Weston PJ, Fraser WD \& Vora JP. Effects of GH replacement on 24-h ambulatory blood pressure and its circadian rhythm in adult GH deficiency. Clinical Endocrinology 200256 431-437.

61 Beshyah SA, Markussis V, Harbourne T, Nicolaides AN \& Johnston DC. Haemostatic mechanisms are normal despite increased vascular mortality in hypopituitary adults. Hormone and Metabolic Research 199325 449-450.

62 Jørgenson JO, Pedersen SA, Ingerslev J, Møller J, Skakkaek NE \& Christiansen JS. Growth hormone therapy in GH-deficient patients, the plasma factor VIII-von Willebrand factor complex, and capillary fragility. Scandinavian Journal of Clinical and Laboratory Investigation $1990 \mathbf{5 0} 417-420$.

63 Klibanski A. Growth hormone and cardiovascular risk markers. Growth Hormone and IGF Research 200313 S109-S115.

64 Lehmann ED, Hopkins KD, Weissberger AJ, Gosling RG \& Sönksen PH. Aortic distensibility in growth hormone deficient adults. Lancet $1993 \mathbf{3 4 1} 309$.

65 Leonsson M, Hulthe J, Oscarsson J, Johannsson G, Wendelhag I, Wikstand $\mathrm{J} \&$ Bengtsson B- $\AA$. Intima-media thickness in cardiovascularly asymptomatic hypopituitary adults with growth hormone deficiency: relation to body mass index, gender, and other cardiovascular risk factors. Clinical Endocrinology 200257 751-759.

66 Markussis V, Beshyah SA, Fisher C, Sharp P, Nicolaides AN \& Johnston DC. Detection of premature atherosclerosis by highresolution ultrasonography in symptom-free hypopituitary adults. Lancet 1992340 1188-1192.

Received 18 June 2009

Accepted 24 June 2009 